\title{
Fungal Pretreatment and Enzymatic Hydrolysis of Genetically-modified Populus trichocarpa
}

\author{
Charles W. Edmunds, ${ }^{\text {a,b }}$ Perry Peralta, ${ }^{\text {a }}$ Ratna R. Sharma-Shivappa, ${ }^{\mathrm{b}}$ Stephen S. Kelley, \\ Vincent L. Chiang, ${ }^{a}$ Zachary D. Miller, ${ }^{a}$ Richard L. Giles, ${ }^{\mathrm{c}}$ Robert W. Sykes, ${ }^{\mathrm{d}}$ \\ Crissa Deoppke, ${ }^{\mathrm{d}}$ Erica Gjersing, ${ }^{\mathrm{d}}$ Mark F. Davis, ${ }^{\mathrm{d}}$ and Ilona Peszlen ${ }^{\mathrm{a}, *}$
}

\begin{abstract}
Fungal pretreatment of Populus trichocarpa wood genetically modified to reduce lignin and alter lignin chemistry is investigated for its effectiveness as an alternative to common pretreatment methods. The goal of this work is to improve biomass utilization for biofuel and biochemical applications by increasing sugar release. Sugar release after enzymatic hydrolysis was measured after various biomass pretreatments (including wood-rot fungus, hot water, and dilute acid). In the wildtype, and in constructs downregulated in $\mathrm{PAL}, 4 \mathrm{CL}$, and $\mathrm{C} 3 \mathrm{H}$, the fungal pretreatment resulted in substantial improvements in sugar yields, up to 2.4-fold increase in glucose yield and 6-fold increase in xylose yield after enzymatic hydrolysis compared to the unpretreated control. However, the effects of fungal pretreatment were inconsistent, and in genetic lines down-regulated in $4 \mathrm{CL}, \mathrm{CCoAOMT}, \mathrm{CAld} 5 \mathrm{H}$, and $\mathrm{C} 3 \mathrm{H}$, fungal pretreatment yielded similar or decreased sugar release after enzymatic hydrolysis.
\end{abstract}

Keywords: Transgenic poplar; Fungal treatment; Ceriporiopsis; Pretreatment; Enzymatic hydrolysis; Lignin

Contact information: a: Department of Forest Biomaterials, North Carolina State University, Raleigh NC 27695; b: Department of Biological and Agricultural Engineering, North Carolina State University, Raleigh NC 27695; c: Adjunct Professor, Departamento de Ciencias y Tecnologia, Universidad Interamericana de Puerto Rico, Arecibo, PR; d: National Renewable Energy Laboratory, Golden CO 80401; *Corresponding author: impeszle@ncsu.edu

\section{INTRODUCTION}

Rising demand for liquid fuels and the finite supply of fossil fuels are driving research for biofuels and alternative energy. Producing bioethanol from lignocellulosics requires pretreatment steps to increase the reactivity of the biomass prior to enzyme hydrolysis and fermentation of sugars. Biomass pretreatments have been identified as one of the most costly steps in the bioethanol conversion process (Mosier et al. 2005). Common pretreatments require harsh chemicals, high temperature, and high energy inputs. Strategies for reducing the costs and complexity of pretreatments are of great interest (Mood et al. 2013). In this work, we explore the effects of genetic modification in combination with alternative pretreatments including fungal, hot water, and dilute acid pretreatments, to increase sugar release after enzymatic hydrolysis.

White-rot fungi (named for the bleached appearance of wood in the advanced stages of degradation) have an exceptional ability to selectivity degrade lignin, and in some cases they leave cell wall carbohydrates largely untouched (Eriksson et al. 1990; Martínez et al. 2005; Wan and Li 2012). 
The white-rot species Ceriporiopsis subvermispora is particularly well-suited for pretreatment of both hardwoods and softwoods due to its ability to selectively degrade lignin without major degradation to carbohydrates during the initial stage of wood degradation (Blanchette et al. 1997; Wan and Li, 2010). Lignin degradation by $C$. subvermispora is largely driven by the extracellular lignin-degrading enzymes manganese peroxidase (MnP) and laccase (Blanchette et al. 1997; Tanaka et al. 2009; Li and Zheng 2019). Erven et al. (2019) demonstrates the main ligninolysis mechanism of single-electron transfer and resulting lignin bond cleavage. Studies show that syringyl (S) lignin may be preferentially degraded over guaiacyl (G) lignin in hardwoods (Choi et al. 2006); however, some studies utilizing different tree species are inconclusive due to the additional physical and morphological differences between species (Obst et al. 1994). Vasco-Correa et al. (2019) reported fungal pretreatment of hardwood, softwood, and miscanthus with $C$. subvermispora followed by enzymatic hydrolysis, and their results indicated that the fungal pretreatment effectiveness was feedstock dependent. More recently, studies utilizing wood from genetically-modified feedstocks have provided further insight into the relationship between lignin chemistry and fungal degradation (Giles et al. 2012; Skyba et al. 2013). In addition, Gaskell et al. (2014) reported increased expression of several oxidoreductases in white rot fungus Phanerochaete chrysosporium using genetically-modified high-S-lignin hybrid poplar as a substrate. This suggests an interaction between the lignin and expression of fungal enzymes.

Treatment with white-rot fungi has been shown to reduce electrical energy during mechanical pulping, increase paper strength, and reduce the environmental impact of pulping (Reid et al. 2010; Akhtar et al. 1997). In addition, wood-degrading fungi have been investigated for lignocellulose biomass pretreatment for the production of biofuels and biochemicals (Wan and Li 2012; Shirkavand et al. 2016). Fungal pretreatment has been investigated for many types of lignocellulosic biomass, including softwoods and hardwoods, grasses (e.g., switchgrass, miscanthus), and agricultural residue such a wheat straw, cotton stalks, corn stover, and others (Wan and Li 2012; Rezania et al. 2020; Sankaran et al. 2020; Vasco-Correa et al. 2015, 2016). In general, these studies show that fungal pretreatment degrades lignin, in many cases with limited losses of cell wall carbohydrates, and it increases biomass reactivity when subjected to enzyme hydrolysis to produce monomer sugars (Sawada et al. 1995; Keller et al. 2003; Shi et al. 2009; Salvachúa et al. 2011; Wan and Li 2011 2012). While these results are promising, the extended pretreatment times (ranging from 14 to 90 days), losses of cellulose and hemicelluloses, and low hydrolysis yields are all practical barriers to commercialization (Wan and Li 2012; Wang et al. 2013).

Genetic engineering has received attention as a means to alter lignin content and composition, and reduce the recalcitrance of lignocellulosic feedstocks for enhanced utilization in biofuel and biochemical applications (Li et al. 2014; Wang et al. 2018). The objective of this study was to test fungal pretreatment with $C$. subvermispora on genetically-modified $P$. trichocarpa followed by enzymatic hydrolysis. In addition, the effectiveness of $C$. subvermispora as the sole pretreatment, or in combination with hot water and dilute acid pretreatments was tested. To our knowledge this is the first study to report the effects of fungal pretreatment on enzymatic hydrolysis utilizing wood from a genetically-modified tree species. These results will increase the understanding of how lignin content and lignin structure influence fungal degradation and enzymatic hydrolysis. 


\section{EXPERIMENTAL}

\section{Wood Samples}

Wood samples from genetically-altered P. trichocarpa (provided by The Forest Biotechnology Group, N. C. State University) were used for fungal pretreatment experiments (Wang et al. 2018). Trees were grown in a greenhouse and harvested after 6 to 8 months. Wood from wildtype $P$. trichocarpa, referred to as WT, and 10 genetic lines with down-regulation of the following lignin biosynthesis genes were used:

- Two lines with high and low expression of cinnamate 3-hydroxylase $(\mathrm{C} 3 \mathrm{H})$ referred to as $\mathrm{C} 3 \mathrm{H}-\mathrm{H}$ and $\mathrm{C} 3 \mathrm{H}-\mathrm{L}$.

- Two lines with high and low expression of coniferaldehyde 5-hydroxylase (CAld5H) referred to as CAld5H-H and CAld5H-L.

- Two lines down-regulated in 4-coumarate coenzyme A ligase (4CL) referred to as 4CL and 4CL3,5.

- One line simultaneously down-regulated in $\mathrm{C} 3 \mathrm{H}$ and cinnamate 4-hydroxylase $(\mathrm{C} 4 \mathrm{H})$ referred to as $\mathrm{C} 3 \mathrm{H}: \mathrm{C} 4 \mathrm{H}$.

- Two lines down-regulated in phenylalanin ammonia lyase referred to as PAL and PAL1-5.

- One line down-regulated in caffeoyl coenzyme A O-methyltransferase (CCoAOMT) referred to as CCoAOMT.

Three stems from each of the $P$. trichocarpa genetic lines and wildtype were selected, and eight 1 -inch sections were cut from the bottom of each stem. All stems were dried at $103+/-2^{\circ} \mathrm{C}$ for $24 \mathrm{~h}$ and weighed to obtain the oven-dry weight. One section from each of the three stems in each genetic line was placed into a $20-\mathrm{mL}$ scintillation vial, producing eight samples per genetic line. A sample consisted of one vial containing three 1-inch stem sections. All samples were then conditioned by adding an appropriate volume of distilled water to each vial so that the water:wood ratio was 1.5 after the inoculation procedure. After $24 \mathrm{~h}$, all samples were sterilized by autoclaving at $121^{\circ} \mathrm{C}$ for $20 \mathrm{~min}$ prior to inoculation. For each genetic line and WT, 4 to 5 samples received the fungal pretreatment and 2 to 3 samples served as sterile controls. Sterilizing the wood samples prior to fungal inoculations was necessary to prevent the growth of any preexisting microorganisms, and thereby isolating the effects of pretreatment with the selected whiterot fungus, $C$ subvermispora. The control samples were sterilized in the same fashion as the samples receiving the fungal treatment in order to account for any effects that the sterilization treatment may have on the wood's chemical composition and sugar release after enzymatic hydrolysis. After the selected pretreatment, wood was milled to pass through a 20 mesh screen and extracted for $24 \mathrm{~h}$ with 95\% ethanol (EtOH) for chemical analysis.

\section{Fungal Pretreatment}

C. subvermispora was cultured on a petri dish with $5 \%$ malt extract agar and incubated at $26{ }^{\circ} \mathrm{C}$ for 7 days. Next a fungal plug was used to inoculate $250 \mathrm{~mL}$ of $5 \%$ malt extract liquid medium (5\% malt extract in deionized water (DI)), and incubated for an additional 30 days at $26^{\circ} \mathrm{C}$. The liquid fungal culture was vigorously shaken to homogenize the fungal mycelium, and $1 \mathrm{~mL}$ was directly added to each vial to inoculate the samples receiving fungal pretreatment. Sterile control samples received $1 \mathrm{~mL}$ of sterile DI water instead of fungal culture. Plastic caps were sterilized with $70 \% \mathrm{EtOH}$, tightened onto the 
vial, then loosened one-quarter turn to allow gas exchange. Samples were incubated at 29 ${ }^{\circ} \mathrm{C}$ in darkness for 30 days. An open container of water was kept in the incubator to keep the humidity high. This fungal pretreatment method is based on previous research towards optimizing fungal degradation for small wood samples subjected to C. subvermispora (Edmunds et al. 2016).

\section{Weight Loss and Cell Wall Component Loss}

After the 30-day incubation period, samples were removed from the incubation containers and surface mycelium was gently removed. Samples were dried under vacuum at $40{ }^{\circ} \mathrm{C}$ for $48 \mathrm{~h}$ then weighed. Percent overall weight loss was calculated using the equation below,

$$
\% \text { Weight Loss }=\left[1-\left[\frac{W_{F}}{W_{o}}\right]\right] \times 100 \% \quad \text { eq. } 1
$$

where $W_{\mathrm{F}}$ is dry weight after fungal pretreatment and $W_{\mathrm{o}}$ is oven dry weight before fungal treatment. Percent component loss for cell wall sugars (glucan, xylan, and mannan) and lignin was calculated by the following equation,

$$
\% \text { Component Loss }=\left[1-\left[\frac{W_{F} \times \% \text { Component }_{F}}{W_{o} \times \% \text { Component }_{S C}}\right]\right] \times 100 \%
$$

where \% Component $t_{\mathrm{F}}$ is the weight percent of the cell wall component measured after fungal pretreatment, and \% Componentsc is the average weight percent of the cell wall component measured in sterile control samples.

\section{Chemical Analysis}

High-throughput pyrolysis molecular beam mass spectroscopy (Py-mbms) was used to estimate lignin content and S/G ratio in sterile control and fungal-pretreated transgenic wood samples. Approximately $5 \mathrm{mg}$ of milled and extracted wood from each sample was weighed then pyrolyzed for $2 \mathrm{~min}$ at $500{ }^{\circ} \mathrm{C}$. The resulting pyrolysis vapors were quenched by free jet expansion in the molecular beam and transported to the mass spectrometer with helium $(2 \mathrm{~L} / \mathrm{min})$. Electron impact ionization of $22.5-\mathrm{eV}$ was used to collect ions in the range of $\mathrm{m} / \mathrm{z}$ ratios of 30 to 450 . To estimate lignin content, the relative intensities of the lignin peaks $m / z=120,124,137,138,150,152,154,164,167,178,180$, $181,182,194$, and 210 were summed and multiplied by a correction factor based on Klason lignin values determined on extracted samples before the sterilization procedure for WT and each genetic line. S/G ratios were determined by dividing the sum of the syringyl peaks at $154,167,168,182,194,208$, and 210 by the sum of the guaiacyl peaks at $124,137,138$, 150,164 , and 178. A detailed description of the analytical pyrolysis procedure and instrumentation can be found in Sykes et al. (2009).

Cell wall carbohydrates were measured on sterile control and fungal-pretreated wood samples by a scaled-down version of the standard NREL Laboratory Analytical Procedure (Sluiter et al. 2008). All samples were analyzed in duplicate.

\section{Hot Water and Dilute Acid Pretreatments and Enzymatic Hydrolysis}

Fungal-treated and sterile control samples (milled and extracted) were subjected to a combined pretreatment (hot water or dilute acid) and enzymatic hydrolysis process followed by sugar release analysis in 96-well reaction plates using the National Renewable 
Energy Laboratory's (NREL) high-throughput biomass protocol (Decker et al. 2009). This procedure consists of weighing $5.0 \pm 0.3 \mathrm{mg}$ of biomass into each well of a 96-well plate; each sample was measured in triplicate. Sterile control and fungal-treated samples were subjected to hot water or dilute acid pretreatment. This creates sample sets receiving a.) only fungal pretreatment, b.) only hot water pretreatment, c.) only dilute acid pretreatment, d.) sequential fungal+hot water pretreatments, and e.) sequential fungal+dilute acid pretreatments. Sterile control (i.e. no pretreatment) served as the control.

For no pretreatment (control) and hot-water pretreatment, $250 \mu \mathrm{L}$ of DI water was added to each sample. In dilute-acid pretreatment, $200 \mu \mathrm{L}$ of $0.4 \%(\mathrm{w} / \mathrm{w}) \mathrm{H}_{2} \mathrm{SO}_{4}$ was added to each sample. Hot-water and dilute-acid pretreated samples were subjected to a steam reactor at $180{ }^{\circ} \mathrm{C}$ for $17.5 \mathrm{~min}$. Next, acid-pretreated samples were neutralized with $20 \mu \mathrm{L}$ of $3.3 \% \mathrm{NaOH}(\mathrm{w} / \mathrm{v})$ and $30 \mu \mathrm{L}$ of $1.0 \mathrm{M}$ citrate buffer ( $\mathrm{pH} 5.0)$ was added. Enzymatic hydrolysis was carried out in all pretreatment conditions by addition of $40 \mu \mathrm{L}$ of $6 \% \mathrm{CTec} 2$ enzyme solution (Novozymes, Franklinton NC) in $1.0 \mathrm{M}$ citrate buffer (pH 5.0), and incubated for $70 \mathrm{~h}$ at $50{ }^{\circ} \mathrm{C}$. After incubation, samples were diluted 10x with DI water. The solution is then diluted 10x again with either glucose oxidase/peroxidase reagent (GOPOD, Megazymes) or xylose dehydrogenase reagent (XDH, Megazymes) in clear microtiter plates to measure glucose and xylose sugars. Microtiter plates with GOPOD and XDH were then measured with UV/VIS spectrometer read at $510 \mathrm{~nm}$ and $340 \mathrm{~nm}$ for GOPOD and $\mathrm{XDH}$, respectively. Six-point calibration curves for glucose and xylose were made by including calibration standards in each 96-well plate.

The hot water and dilute acid pretreatment conditions were chosen based on previous work completed at the Department of Energy's National Renewable Energy Laboratory on their high-throughput (HTP) biomass pipeline. These process conditions are meant to provide a sub-optimal pretreatment in order to provide incomplete sugar release so that the digestibility of the feedstocks based on a) their composition as affected by genetic modification and 2) fungal pretreatment effectiveness can be better determined. In addition, a relatively high enzyme loading of $40 \mu \mathrm{L}$ of $6 \% \mathrm{CTec} 2$ is meant to reduce effects of enzyme activity, thereby better isolating the effects of pretreatment effectiveness (Decker et al. 2015).

Glucose and xylose yield after enzymatic hydrolysis were calculated based on the average chemical composition of sterile control (untreated) wood. This accounted for carbohydrate losses due to fungal degradation, and the following equation was used:

$$
\begin{aligned}
& \% \frac{\text { Glucose }}{\text { Xylose }} \text { Yield }= \\
& \qquad \frac{\text { glucose } / \text { xylose released after enzymatic hydrolsis }}{\text { glucose } / \text { xylose in sterile control sample }} \times 100 \%
\end{aligned}
$$

\section{Statistical Analysis}

A general linear model (proc GLM) and Tukey's mean separation (SAS, v. 9.4, SAS Institute Inc.) was used to test for significant differences in mean weight loss values after fungal pretreatment between samples of WT, and different genetic constructs. Microsoft Excel was used to calculate the $\mathrm{r}$ value and $p$ value for correlations between $\%$ lignin content and \% glucose and \% xylose yields. 


\section{RESULTS AND DISCUSSION}

\section{Chemical Composition of Untreated Wood}

There were considerable variations in the chemical composition between the WT and transgenic lines sterile control (untreated) samples. Tables 1 and 2 show total lignin content, S/G ratio, and structural carbohydrate content in the sterile control $P$. trichocarpa samples. Lignin content ranged from $10 \mathrm{wt} . \%$ in C3H-L to $22 \mathrm{wt} . \%$ in WT, and Py-mbms estimated S/G ratios ranging from 0.3 to 1.8 in Cald5H-L and WT, respectively. The Hlignin content was not measured directly in these samples; however, Wang et al. (2018) showed high $\mathrm{H}$-lignin content in $\mathrm{C} 3 \mathrm{H}$ down-regulated $P$. trichocarpa. The wood samples used for this work were a sub-set of samples studied by Wang et al. (2018). For example, Wang et al. (2018) reported C3H3 down-regulated samples to contain $45 \mathrm{wt} . \% \mathrm{H}$ lignin monomers, and $\mathrm{C} 3 \mathrm{H}: \mathrm{C} 4 \mathrm{H}$ down-regulated sample to contain $33 \mathrm{wt} . \% \mathrm{H}$ lignin as measured by 2D NMR. Transgenic lines were categorized based on lignin characteristics into the following groups: slight to moderately reduced lignin (including lines PAL, PAL1-5, 4CL, 4CL3,5, and CCoAOMT); increased G-lignin (including CAld5H-L and CAld5H-H), and significantly reduced lignin content and a concurrent increase in $\mathrm{H}$ lignin (including $\mathrm{C} 3 \mathrm{H}-$ $\mathrm{L}, \mathrm{C} 3 \mathrm{H}-\mathrm{H}$, and $\mathrm{C} 3 \mathrm{H}: \mathrm{C} 4 \mathrm{H}$ ) as outlined in Table 1.

\section{Fungal Pretreatment Alone \\ Weight loss}

Weight loss values after the 30-day fungal pretreatment period ranged from 7 to 19 wt.\%, and substantial differences were seen between WT with $8.5 \%$ weight loss and samples from several transgenic lines (Table 2). The ANOVA results demonstrate that both the fungal pretreatment as well as the genetic line had a significant effect on weight loss ( $p$ $<0.0001$ ). WT and many transgenic lines fall within the range of reported weight loss values utilizing $C$. subvermispora to treat hardwoods, which ranges from 6 to $15 \mathrm{wt} . \%$ after 30 days of treatment (Choi et al. 2006; Giles et al. 2011; Wan and Li 2011). However, samples from several genetically-modified lines exhibited higher weight loss than is generally reported, indicating that these transgenic lines were less resistant to fungal decay. In addition, no clear correlation between the initial lignin content or the initial S/G ratio and weight loss after fungal degradation was observed.

\section{Cell wall component loss after fungal pretreatment}

Lignin selectivity of $C$. subvermispora was high in WT and several other transgenic lines. Also, in general, when weight loss was in the low to moderate range (7 to $15 \mathrm{wt} . \%$ ), cellulose loss was lower, ranging from 1 to $10 \mathrm{wt} . \%$ reduction. High lignin selectivity was expected based on the lignin-selective nature of C. subvermispora (Otjen et al. 1987). However, when the overall measured weight loss after fungal pretreatment was in the higher range (>17\%), cellulose loss was also more substantial, ranging from 21 to $25 \mathrm{wt} . \%$. In these cases, it is likely that the fungal degradation had exceeded the initial ligninselective decay period, suggesting that these samples were degraded more quickly and to a greater extent.

Based on S/G ratio determined by Py-mbms (Table 1), there was a decrease in the $\mathrm{S} / \mathrm{G}$ ratio after fungal pretreatment for all samples, with the exception of CCoAOMT, Cald5H-L, and Cald5H-H, where the S/G ratio was unchanged or slightly increased. This suggests that with these exceptions, fungal pretreatment resulted in higher degradation of the S-lignin relative to G-lignin. 
Table 1. Chemical Composition of Sterile Control (untreated) and Fungal-Pretreated Wildtype and Genetically-Modified $P$. trichocarpa Wood Samples

\begin{tabular}{|c|c|c|c|c|c|c|c|c|}
\hline Construct & Treatment & $\mathrm{N}$ & Glucan & Xylan & Mannan & $\mid \begin{array}{l}\% \text { Lignin } \\
\text { Content }\end{array}$ & S/G ratio* & Description \\
\hline \multirow{2}{*}{ WT } & $S C$ & 3 & $41.4(0.3)^{*}$ & $14.1(08)$ & $2.3(0.3)$ & $21.8(0.4)$ & $1.8(0.1)$ & \multirow{2}{*}{-Wildtype } \\
\hline & $\mathrm{F}$ & 5 & $44.9(0.6)$ & $13.8(0.7)$ & $2.3(0.4)$ & $14.5(0.7)$ & $1.4(0.1)$ & \\
\hline \multirow{2}{*}{ PAL } & $S C$ & 3 & $42.8(0.8)$ & $13.7(0.2)$ & $2.5(0.6)$ & $18.4(0.5)$ & $1.8(0.0)$ & \multirow{10}{*}{$\begin{array}{l}\text { Slightly to } \\
\text { Moderately } \\
\text { Reduced } \\
\text { Lignin } \\
\text { Content }\end{array}$} \\
\hline & $\mathrm{F}$ & 5 & $45.2(0.8)$ & $12.6(1.0)$ & $2.5(0.6)$ & $14.1(0.4)$ & $1.5(0.0)$ & \\
\hline \multirow{2}{*}{ PAL1-5 } & $S C$ & 3 & $42.8(1.3)$ & $12.5(1.4)$ & $2.2(0.4)$ & $17.6(1.3)$ & $1.8(0.1)$ & \\
\hline & $\mathrm{F}$ & 5 & $45.3(0.9)$ & $11.6(0.7)$ & $2.0(0.5)$ & $14.1(0.5)$ & $1.6(0.1)$ & \\
\hline \multirow{2}{*}{$4 C L$} & $S C$ & 3 & $42.1(0.2)$ & $13.5(0.2)$ & $1.6(0.6)$ & $18.8(0.1)$ & $1.8(0.1)$ & \\
\hline & $\mathrm{F}$ & 5 & $45.5(1.0)$ & $14.8(0.5)$ & $1.7(0.4)$ & $13.5(0.8)$ & $1.5(0.1)$ & \\
\hline \multirow{2}{*}{ 4CL3,5 } & $S C$ & 3 & $43.1(0.9)$ & $11.5(0.1)$ & $2.0(0.7)$ & 19.1 (0.3) & $1.7(0.0)$ & \\
\hline & $F$ & 5 & $42.1(0.9)$ & $14.9(0.3)$ & $1.7(0.0)$ & $16.5(1.0)$ & $1.6(0.1)$ & \\
\hline \multirow{2}{*}{ CCOAOMT } & $S C$ & 3 & $46.0(1.5)$ & $11.2(0.9)$ & $1.7(0.3)$ & $17.6(0.3)$ & $1.6(0.1)$ & \\
\hline & $\mathrm{F}$ & 4 & $42.3(0.9)$ & $13.7(0.8)$ & $1.5(0.1)$ & $17.5(0.2)$ & $1.6(0.1)$ & \\
\hline \multirow{2}{*}{ CAld5H-L } & $S C$ & 2 & $44.1(1.5)$ & $12.0(0.2)$ & $1.8(0.6)$ & $20.9(0.1)$ & $0.3(0.0)$ & \multirow{4}{*}{$\begin{array}{l}\text { Increased G } \\
\text { Lignin }\end{array}$} \\
\hline & $\mathrm{F}$ & 4 & $42.4(1.2)$ & $11.7(0.7)$ & $1.7(0.2)$ & $18.6(0.5)$ & $0.4(0.0)$ & \\
\hline \multirow{2}{*}{ CAld5H-H } & $S C$ & 3 & $45.2(0.4)$ & $12.2(0.3)$ & $2.2(0.1)$ & $20.8(0.4)$ & $1.1(0.0)$ & \\
\hline & $\mathrm{F}$ & 5 & $43.7(1.8)$ & $12.7(0.9)$ & $1.8(0.4)$ & $19.3(0.9)$ & $1.1(0.0)$ & \\
\hline \multirow{2}{*}{$\mathrm{C} 3 \mathrm{H}-\mathrm{L}$} & $S C$ & 2 & $42.1(0.5)$ & $16.6(0.8)$ & $2.0(0.3)$ & $9.9(0.3)$ & $0.9(0.0)$ & \multirow{6}{*}{$\begin{array}{l}\text { Severely } \\
\text { Reduced } \\
\text { Lignin } \\
\text { Content and } \\
\text { Increased H- } \\
\text { Lignin }\end{array}$} \\
\hline & $\mathrm{F}$ & 5 & $44.2(0.9)$ & $14.9(0.5)$ & $1.8(0.2)$ & $9.2(0.4)$ & $0.8(0.1)$ & \\
\hline \multirow{2}{*}{$\mathrm{C} 3 \mathrm{H}-\mathrm{H}$} & $S C$ & 3 & $43.1(0.3)$ & $16.6(0.9)$ & $2.8(0.4)$ & $13.5(0.3)$ & $1.4(0.0)$ & \\
\hline & $\mathrm{F}$ & 5 & $46.8(0.6)$ & $15.4(0.8)$ & $2.7(0.3)$ & $9.8(0.3)$ & $1.0(0.1)$ & \\
\hline \multirow[b]{2}{*}{$\mathrm{C} 3 \mathrm{H}: \mathrm{C} 4 \mathrm{H}$} & $S C$ & 3 & $44.0(0.2)$ & $16.1(0.9)$ & $2.9(0.5)$ & $13.5(0.8)$ & $1.2(0.1)$ & \\
\hline & $F$ & 5 & $44.8(1.4)$ & $15.3(0.5)$ & $2.9(0.6)$ & $11.1(0.3)$ & $1.1(0.1)$ & \\
\hline
\end{tabular}

* Parenthesis indicate standard deviation; ** Lignin content and S/G ratio measured by Py-MBMS; "SC" denotes "sterile control" and "F" denotes "fungal pretreatment" 
Table 2. Overall Weight Loss, and Cell Wall Component (Cellulose, Hemicellulose, and Lignin) Loss after Fungal Pretreatment for Wildtype and Genetically-Modified P. trichocarpa Wood Samples

\begin{tabular}{|c|c|c|c|c|c|}
\hline \multirow{2}{*}{ Construct } & \multirow{2}{*}{$\begin{array}{c}\text { Overall Wt. Loss } \\
(\%)\end{array}$} & \multicolumn{3}{|c|}{ Cell Wall Component Loss (\%) } & \multirow[t]{2}{*}{ Description } \\
\hline & & Cellulose $^{* *}$ & Hemicellulose ${ }^{\star \star \star}$ & Lignin & \\
\hline WT & $8.5(0.5)^{*} \mathrm{D}$ & $0.8(1.2)$ & $9.9(6.3)$ & $39.1(3.1)$ & Wildtype \\
\hline PAL & $7.1(3.3) \mathrm{D}$ & $1.8(5.1)$ & $13.5(7.4)$ & $28.7(2.9)$ & \multirow{5}{*}{$\begin{array}{l}\text { Slightly Reduced } \\
\text { Lignin Content }\end{array}$} \\
\hline Pal1-5 & $6.8(0.1) \mathrm{D}$ & $1.3(2.0)$ & $13.6(7.6)$ & $25.6(2.5)$ & \\
\hline $4 \mathrm{CL}$ & $15.3(1.1) \mathrm{BC}$ & $8.3(1.0)$ & $5.4(7.0)$ & $39.3(4.5)$ & \\
\hline 4CL3,5 & $19.4(1.9) \mathrm{A}$ & $21.4(3.2)$ & $5.2(8.6)$ & $30.2(5.4)$ & \\
\hline CCOAOMT & $18.6(2.0) \mathrm{A}$ & $25.1(10.8)$ & $6.9(2.9)$ & 19.3(2.9) & \\
\hline Cald5H-L & $19.1(1.2) \mathrm{A}$ & $22.4(8.9)$ & $21.1(5.3)$ & $28.2(1.2)$ & \multirow{2}{*}{$\begin{array}{l}\text { Increased G- } \\
\text { Lignin }\end{array}$} \\
\hline Cald5H-H & $17.9(0.9) \mathrm{AB}$ & $21.4(3.5)$ & $21.2(10.8)$ & $24.0(3.8)$ & \\
\hline $\mathrm{C} 3 \mathrm{H}-\mathrm{L}$ & $14.2(1.2) \mathrm{C}$ & $10.0(1.6)$ & $22.9(3.9)$ & $20.3(4.0)$ & \multirow{3}{*}{$\begin{array}{l}\text { Severely } \\
\text { Reduced Lignin } \\
\text { Content and } \\
\text { Increased H- } \\
\text { Lignin }\end{array}$} \\
\hline $\mathrm{C} 3 \mathrm{H}-\mathrm{H}$ & $7.4(0.3) \mathrm{D}$ & $-0.7(1.1)$ & $13.6(4.9)$ & $33.1(2.2)$ & \\
\hline C3H:C4H & $7.5(0.9) \mathrm{D}$ & $5.8(2.7)$ & $11.1(5.0)$ & $23.8(1.8)$ & \\
\hline
\end{tabular}

${ }^{*}$ Parenthesis indicate standard deviation ${ }^{* *}$ Cellulose calculated by glucan; ${ }^{* * *}$ hemicellulose calculated by the sum of xylan and mannan; Different letters indicate significant difference $(\alpha=0.05)$ in the mean of overall wt. loss.

These results are consistent with Obst et al. (1994) and Davis et al. (1994), who reported that as fungal degradation progressed the $\mathrm{S} / \mathrm{G}$ ratio decreased in several species of hardwoods degraded by several white rot fungi such as Trametes versicolor and $P$. chrysosporium. In addition, Choi et al. (2006) reported that aspen wood degraded by $C$. subvermispora resulted in cleavage of $\beta-\mathrm{O}-4$ linkages, and degradation of $\mathrm{S}$ lignin appeared to be preferred. Microscopic analysis has demonstrated the decay pattern of white rot fungi as beginning in the cell lumen and progressively moving toward the middle lamella and cell corners (Blanchette 1991). It has been suggested that $S$ lignin reduction and decreased $\mathrm{S} / \mathrm{G}$ ratio following white rot decay is consistent with preferential degradation of the Slignin-rich cell wall, as opposed to the G-lignin-rich middle lamella and cell corner (Davis et al. 1994; Obst et al. 1994).

\section{Degradation of lines with high G lignin}

The two Cald5H down-regulated samples had among the highest weight loss with $19 \%$ and $18 \%$ for Cald5H-L and Cald5H-H, respectively. Both Cald5H down-regulated samples had low S/G ratio values and normal lignin content values (measured by PyMBMS), indicating elevated G lignin concentrations compared to the WT. For example, Cald5H-L had an estimated S/G ratio of 0.3, as determined by Py-mbms. Previous studies on CAld5H up-regulated poplar with high $\mathrm{S}$ lignin content have reported increased decay resistance against $C$. subvermispora (Giles et al. 2012; Skyba et al. 2013). Giles et al. (2012) reported significantly less lignin degradation in high $\mathrm{S}$ lignin quaking aspen compared to the control, although overall weight loss was higher due to greater degradation of carbohydrates. Skyba et al. (2013) reported significantly reduced weight loss and reduced lignin loss in high $\mathrm{S} / \mathrm{G}$ ratio samples compared to the control, and hypothesized that lignin with high proportions of $\mathrm{S}$ monomers have more $\beta-\mathrm{O}-4$ linkages, resulting in a more linear lignin polymer than in lignin with higher amounts of $\mathrm{G}$ monomers. Based on 
this rationale, the Cald5H down-regulated samples examined in this study, may be more highly branched, leading to greater degradation by the fungus. The degree of lignin loss in the Cald5H down-regulated samples was lower (24 to $28 \mathrm{wt} . \%$ ), while carbohydrate loss was higher than many of the other genetic lines. One possible explanation is that in the latter stages of the fungal pretreatment the white-rot fungi may have relied more heavily on carbohydrate as a carbon source, leading to more vigorous growth and catabolism. It is possible that chemical or physical properties, other than those reported in this study, are altered a result of the genetic modification. Due to the complexity of these various aspects of wood properties and fungal degradation, the reason for the high susceptibility to fungal degradation of the Cald5H samples is difficult to isolate.

\section{Degradation of lines with slightly and moderately reduced lignin content}

Compared to WT, significantly higher weight loss was observed in samples 4CL, 4CL3,5 and CCoAOMT with weight losses of 15\%, 19\%, and 19 wt. \%, respectively. These three samples had slight to intermediate reductions in lignin content due to the genetic modification with 19\%, 19\%, and 18 wt.\% initial lignin content for 4CL, 4CL3,5, and CCoaOMT, respectively. This is consistent with the results of Giles et al. (2012), who showed that genetically-modified 4CL-reduced poplar wood exhibited greater loss of cellulose during fungal pretreatment. This is consistent with the higher loss of cellulose due to higher fungal growth and ligninolytic activity. In contrast, both PAL down-regulated samples showed weight loss similar to WT indicating that higher levels of lignin content did not significantly alter the decay resistance of the wood.

\section{Degradation of lines with severely reduced lignin content}

The transgenic line $\mathrm{C} 3 \mathrm{H}-\mathrm{L}$ with its significant reduction in lignin exhibited higher weight loss after fungal pretreatment than WT, while the other two lines with significant reductions in lignin, e.g., $\mathrm{C} 3 \mathrm{H} 3-\mathrm{H}$ and $\mathrm{C} 3 \mathrm{H}: \mathrm{C} 4 \mathrm{H}$, had similar weight loss to WT. It appears that there were several competing effects in these samples, including reduced lignin content and an increased proportion of $\mathrm{H}$ lignin, as well as changes in anatomical cell wall structure in these genetically-modified samples (Miller et al. 2019). Table 1 shows that in many lines the $\mathrm{S} / \mathrm{G}$ ratio decreased after the fungal pretreatment, which was likely caused by relatively higher degradation of the S-lignin-rich secondary cell wall compared to G-lignin-rich middle lamella (Table 1). The individual effects of lignin reduction and incorporation of $\mathrm{H}$ lignin, and their interactions, obscure these results.

It is generally agreed that increased lignin content leads to increased resistance towards biological degradation (Kirk et al. 1984). However, in this study, there was no clear trend between the initial lignin content and weight loss after fungal pretreatment among various wood samples. This may be an effect of the lignin-specific nature of $C$. subvermispora, which exhibits low cellulolytic capacity (Fernandez-Fueyo et al. 2012). As discussed previously, genetic perturbations influence both the chemical and physical properties of both the lignin and carbohydrates. For example, Miller et al. (2019) showed significant anatomical differences in a subset of these genetically-modified $P$. trichoparpa specimens. Thus, the effects of changes in wood's lignin content on its resistance to fungal degradation is confounded by these anatomical changes.

\section{Enzymatic Hydrolysis}

In a second set of experiments, hot water or dilute acid pretreatments were applied to fungal-treated and sterile control samples. Sugar release following the various 
pretreatments and enzymatic hydrolysis were measured. The addition of hot water or dilute acid pretreatment following the fungal pretreatment and then enzymatic hydrolysis yielded mixed sugar release results among the various transgenic samples tested. The ANOVA results demonstrate that pretreatment type had a significant effect on both glucose yield and xylose yield $(p<0.0001)$. Figure 1 shows the percent yield of glucose and xylose following various pretreatments and enzymatic hydrolysis relative to the amount of glucose or xylose in the sterile control samples (i.e., no pretreatment); thus, carbohydrate loss due to the fungal pretreatment was accounted for.
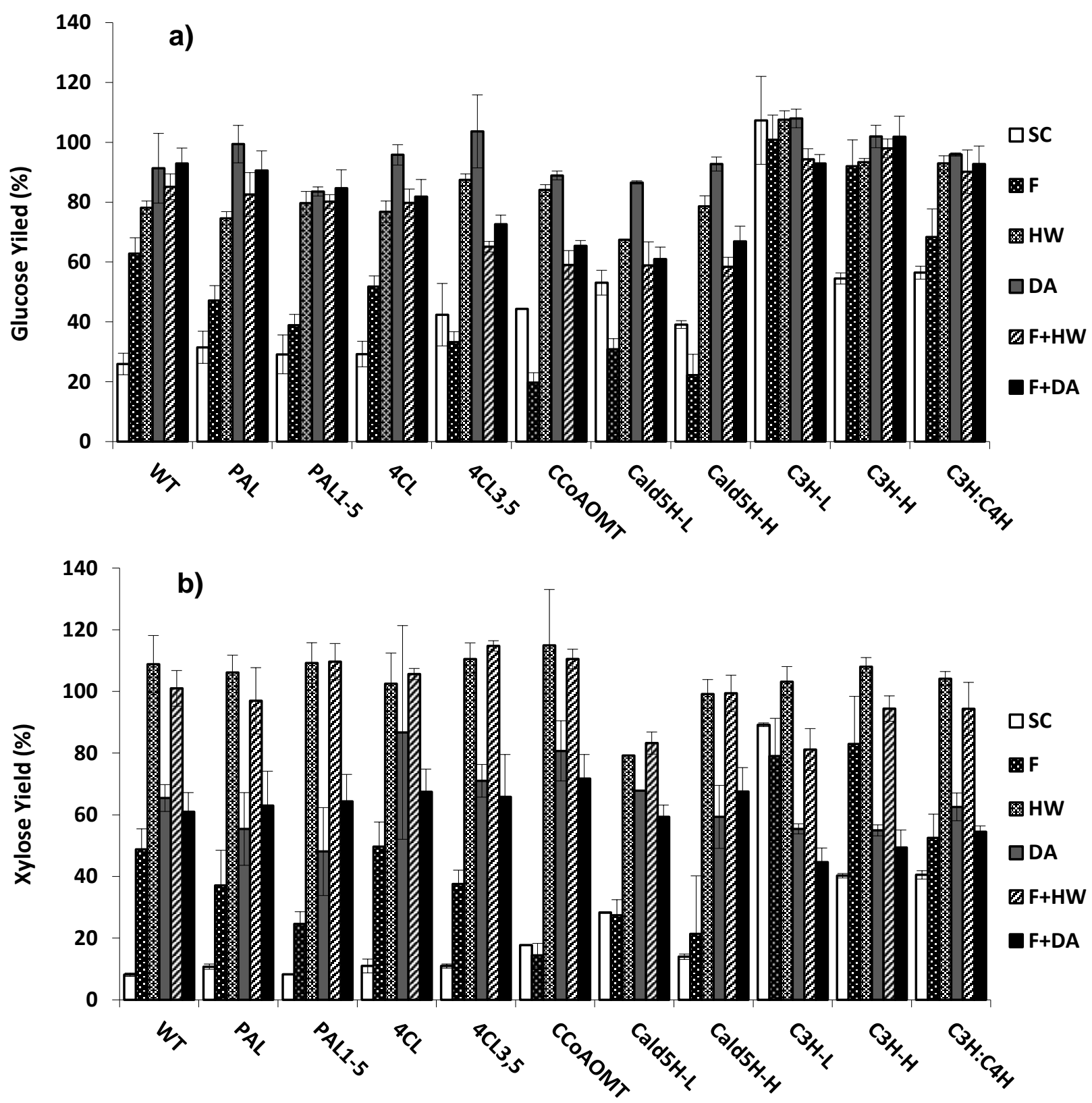

Fig. 1 Yield of a) glucose and b) xylose after 72-h enzymatic hydrolysis for sterile control and various treatment regimes. Yield percent is based on chemical composition of sterile control (untreated) wood; legend abbreviations for the treatments: $\mathrm{SC}=$ sterile control (i.e. no pretreatment), $\mathrm{F}=$ fungal alone, $\mathrm{HW}=$ hot water alone, $\mathrm{DA}=$ dilute acid alone, $\mathrm{F}+\mathrm{HW}=$ sequential fungal followed by hot water, and $F+D A=$ sequential fungal followed by dilute acid. 
The box plots in Fig. 2 show the distribution of glucose and xylose yields (after pretreatments and enzymatic hydrolysis) for the various pretreatments tested with all sample types (transgenic and wildtype) grouped together. As expected, the SC samples have the lowest average sugar release values. The fungal alone pretreatment resulted in higher average sugar yields; however, there was a large variance among the various transgenic wood samples tested. The hot water alone pretreatment resulted in higher average sugar yields than the fungal alone pretreatment. The dilute acid alone pretreatment resulted in the greatest average glucose yield. However, the xylose yields for both dilute acid alone and sequential fungal and dilute acid pretreatment was lower than hot water alone and sequential fungal and hot water pretreatment. This is likely caused by xylose degradation in acidic conditions. The sequential fungal and hot water pretreatments resulted in similar average glucose and xylose sugar yields to the hot water alone pretreatment.
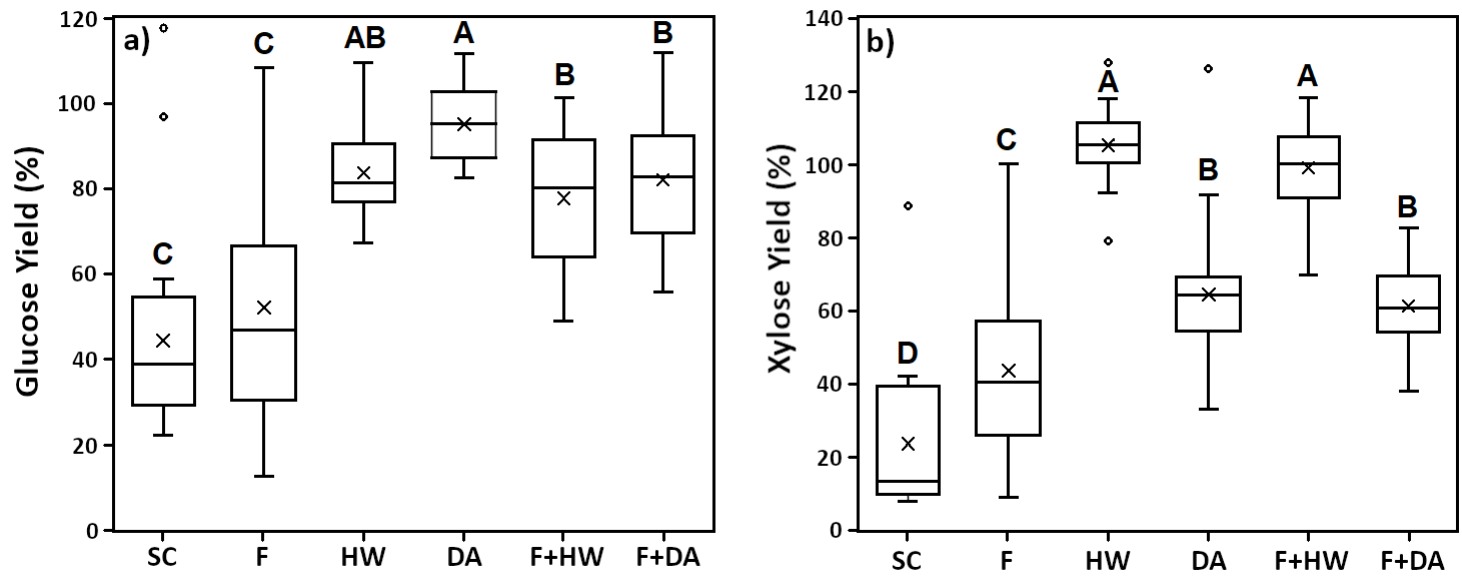

Fig. 2. Box plots showing the distribution of a) glucose yield and b) xylose yield after various pretreatment regimes and 72-h enzymatic hydrolysis. Yield percent based on chemical composition of sterile control (untreated) wood; abbreviations denote the following pretreatments: $\mathrm{SC}=$ sterile control (i.e. no pretreatment), $\mathrm{F}=$ fungal alone, $\mathrm{HW}=$ hot water alone, $\mathrm{DA}=$ dilute acid alone, $\mathrm{F}+\mathrm{HW}=$ sequential fungal followed by hot water, and $\mathrm{F}+\mathrm{DA}=$ sequential fungal followed by dilute acid. Different letters indicate significantly different $(\alpha=0.05)$ mean glucose or xylose yields between the different treatments.

\section{Effect of fungal pretreatment alone}

Using only the fungal pretreatment, WT, PAL, 4CL, and $\mathrm{C} 3 \mathrm{H}-\mathrm{H}$ showed large increases in glucose and xylose yields compared to the sterile controls (Fig 1). WT showed $63 \%$ glucose yield and $49 \%$ xylose yield after enzymatic hydrolysis, representing 2.4-fold and 6-fold increase compared to the sterile control. Following a similar trend, VascoCorrea et al. (2019) reported a $\sim 35 \%$ glucose yields (representing a 4.5 -fold increase compared to the control) for hardwood (Fraxinus americana) and a $\sim 20 \%$ xylose yield (representing a 10-fold increase compared to the control) after a 14-day fungal pretreatment with $C$. subvermispora. The differences in yield between this study and that of VascoCorrea et al. (2019) may be explained by differences in the hardwood species used, differences in the incubation time, as well as the use of sterilized vs. non-sterilized feedstocks. 
Fungal-treated 4CL resulted in similar yields as WT, while fungal-treated $\mathrm{C} 3 \mathrm{H}-\mathrm{H}$ resulted in high yields of $91 \%$ glucose and $83 \%$ xylose, representing yield increases of 1.7fold for glucose and 2.1-fold for xylose, compared to the sterile control of the same transgenic line.

Fungal-treated lines CCoAOMT, Cald5H-L, and Cald5H-H resulted in lower glucose yields compared to their sterile control counterparts after enzymatic hydrolysis (Fig. 1). These samples had among the highest overall weight loss and glucose reduction during the initial fungal pretreatment, consistent with the easily accessible cellulose fraction being removed by the fungus and leaving behind a more recalcitrant fraction resulting in reduced hydrolysis.

Genetic line C3H-L showed near $100 \%$ glucose yield and $89 \%$ xylose yield in sterile control samples (i.e. no pretreatment), and the fungal pretreatment provided no benefit. This is likely caused by the severe lignin reduction with only $9.9 \%$ lignin content and associated low recalcitrance, which were observed in the $\mathrm{C} 3 \mathrm{H}-\mathrm{L}$ line. Chen and Dixon (2007) reported high enzymatic hydrolysis efficiency $(55 \%)$ in $\mathrm{C} 3 \mathrm{H}$ down-regulated alfalfa with severely reduced lignin content, which is consistent with these results. In addition, Wang et al. (2018) reported an increase in sugar release following enzymatic hydrolysis and lower lignin content in genetically-modified $P$. trichocarpa.

\section{Effect of hot water alone and dilute acid alone pretreatments}

In most cases, the hot water pretreatment alone resulted in higher yields than the fungal pretreatment alone. Exceptions to this case included $\mathrm{C} 3 \mathrm{H}-\mathrm{L}$ and $\mathrm{C} 3 \mathrm{H}-\mathrm{H}$, where yields of glucose and xylose were similar between fungal pretreatment alone and hot water pretreatment alone. Considering the dilute acid pretreatment alone, yield of glucose was higher in WT and most genetic lines compared to fungal pretreatment alone, and slightly higher or similar to the hot water pretreatment alone. Similar to the hot water only pretreatments, the dilute acid only pretreatment for genetic lines $\mathrm{C} 3 \mathrm{H}-\mathrm{L}$ and $\mathrm{C} 3 \mathrm{H}-\mathrm{H}$ yielded similar glucose and xylose yields to that of fungal pretreatment alone. Yields of xylose were consistently lower for the dilute acid pretreatment, which can be attributed to xylose degradation by the acidic pretreatment (Alvira et al. 2010).

\section{Effect of sequential pretreatments}

As expected, with a few exceptions, fungal pretreatment followed by hot water pretreatment resulted in higher glucose and xylose yields than fungal pretreatment alone. The glucose and xylose yields for the combination of fungal pretreatment followed by hot water pretreatment was essentially the same as hot water pretreatment alone. These results indicate that the beneficial effects of fungal pretreatment were diminished when hot water pretreatment was added. The exceptions to this trend are $\mathrm{C} 3 \mathrm{H}-\mathrm{L}$, for which the sterile control (i.e., no pretreatment) and fungal pretreatment alone resulted in the same sugar release as sequential fungal and hot water pretreatment, and $\mathrm{C} 3 \mathrm{H}-\mathrm{H}$, where the fungal pretreatment alone produced similar results as the sequential fungal and hot water pretreatment.

Previous research has demonstrated that hot water pretreatment solubilizes hemicelluloses and improves enzymatic hydrolysis yields (Xiao et al. 2011). Wang et al. (2012) reported that sequential fungal (L. betulina C5617) and liquid hot water (140 to 200

${ }^{\circ} \mathrm{C}$ ) pretreatment on Populus tomentosa resulted in 1.15 to 2.66-fold increase of glucose yield after enzymatic hydrolysis compared to hot water pretreatment alone. Wang et al. (2012) found that the beneficial effects of sequential fungal and hot water pretreatments 
were more pronounced when hot water pretreatment was at a lower temperature due to decreased severity. In the current study, hot water pretreatment was applied at $180{ }^{\circ} \mathrm{C}$ for $17.5 \mathrm{~min}$, and if lower temperature or reduced residence time were used, synergistic effects of sequential fungal and hot water pretreatments may have been observed.

The sequential fungal and dilute acid pretreatment showed increased yield of glucose with respect to the fungal pretreatment alone, except in lines $\mathrm{C} 3 \mathrm{H}-\mathrm{L}$ and $\mathrm{C} 3 \mathrm{H}-\mathrm{H}$, in which the results were similar. The yield of xylose was similar between fungal pretreatment alone and sequential fungal and acid pretreatment for $\mathrm{WT}$ and $\mathrm{C} 3 \mathrm{H}: \mathrm{C} 4 \mathrm{H}$, but higher in the case of fungal pretreatment alone for lines $\mathrm{C} 3 \mathrm{H}-\mathrm{L}$ and $\mathrm{C} 3 \mathrm{H}-\mathrm{H}$. The sequential fungal and dilute acid pretreatment showed no increase in yield compared to dilute acid pretreatment alone. This suggests that the more severe dilute acid pretreatment overwhelmed the benefits of the fungal pretreatment.

For samples 4CL3,5, CCoAOMT, Cald5H-L, and Cald5H-H, for which the fungal pretreatment resulted in significant degradation of the original glucan (18 to 19\%), dilute acid pretreatment alone resulted in greater glucose yields than the sequential fungal and dilute acid pretreatment. Similar to the dilute acid pretreatment alone, there was a reduced xylose yield for the sequential fungal and dilute acid pretreatment.

\section{Sugar yield correlations}

Lignin content is considered to be one of the main indicators of biomass recalcitrance (Studer et al. 2011; Min et al. 2012). Previous research has demonstrated an inverse correlation between lignin content and sugar release after enzymatic hydrolysis (Chen and Dixon 2007; Studer et al. 2011; Min et al. 2012; Wang et al. 2018). Similar to these past results, Fig. 3 shows there is a strong correlation between lignin content and sugar release for both glucose $(\mathrm{R} 2=0.68)$ and xylose $(\mathrm{R} 2=0.79)$ after enzymatic hydrolysis for both the fungal alone pretreated and non-pretreated (sterile control) samples.
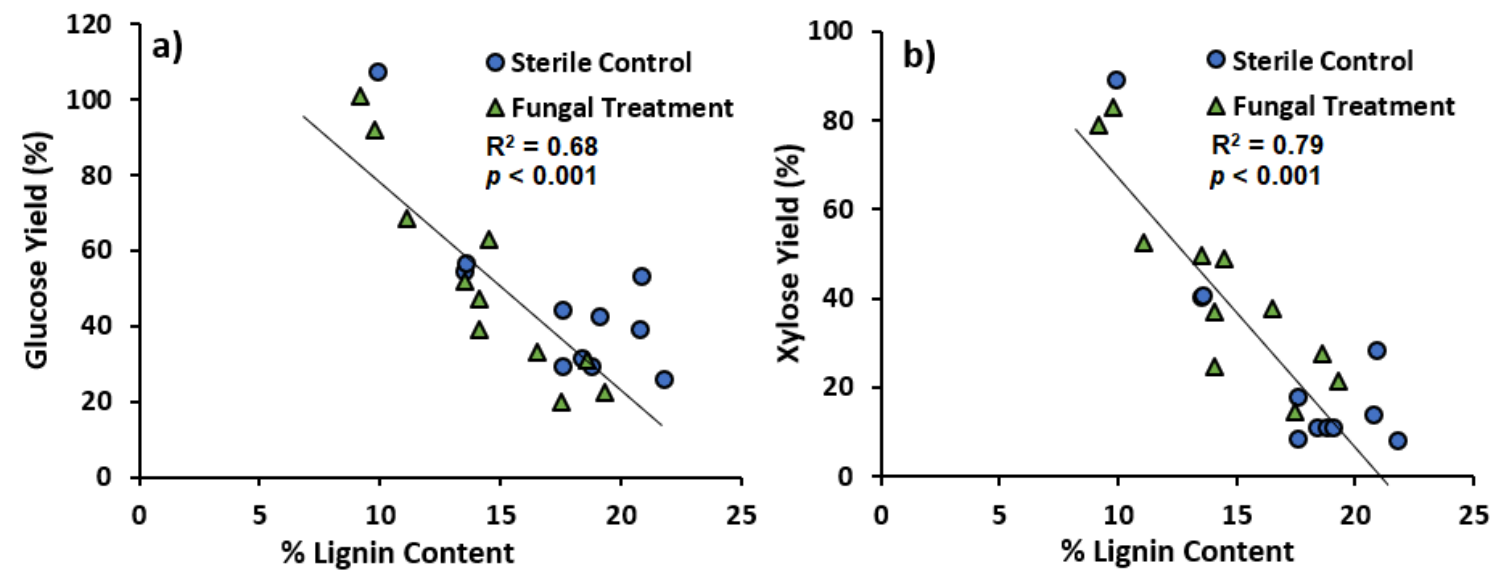

Fig. 3. Correlation between \% lignin content and a) glucose yield and b) xylose yield for sterile control and fungal alone treated $P$. trichocarpa samples after enzymatic hydrolysis; glucose and xylose yields are based on chemical composition of untreated (sterile control) wood.

\section{Summary of Pretreatment and Enzymatic Hydrolysis Results}

Biomass susceptibility to enzymatic hydrolysis after pretreatments yielded mixed results among the different genetic modifications. These differences can have several different, inter-related mechanisms that include both the initial recalcitrance of the 
biomass, wood anatomical differences, and the effectiveness of the fungal treatment. Notably, fungal pretreatment of WT and $\mathrm{C} 3 \mathrm{H}-\mathrm{H}$ resulted in substantial improvements of sugar yields after enzymatic hydrolysis. Furthermore, transgenic line C3H-L, with its significantly lower lignin content, yielded nearly complete conversion of glucose and xylose without any pretreatment indicating very low initial recalcitrance. These genetic lines exhibit low recalcitrance and could be promising as a renewable feedstock if their silvicultural traits were acceptable. However, severe lignin reductions have been reported to impair growth rate and physiological characteristics of the plant (Coleman et al. 2008; Novaes et al. 2010; Voelker et al. 2010; Li et al. 2014). The physiological changes, growth rate, insect and disease resistance, and hardiness must be considered in order to produce commercially attractive feedstock.

It is important to recognize that the time required (generally 14 to 90 days) for fungal pretreatment can be a disadvantage when compared to chemical or physical pretreatment techniques (Shirkavand et al. 2016). However, the reduced energy and chemical inputs of fungal pretreatment may offset this disadvantage. In this study, we utilized a 30-day incubation period based on previous work (Edmunds et al. 2016) as well as this being a commonly utilized time in previous research. Depending on the initial chemical composition and physical characteristics of the feedstock utilized, a shorter incubation time may yield acceptable results. We suggest the optimization of fungal pretreatment time for different feedstocks as an important topic for further work.

\section{CONCLUSIONS}

1. Fungal pretreatment can be effective in improving sugar yield on enzymatic hydrolysis of genetically-modified poplar; however, it is not as efficient as the standard hot-water or dilute-acid pretreatment methods.

2. Sequential pretreatments afford no or minimal improvement over standard individual pretreatments on amount of sugar yield.

3. Genetic lines with severely reduced lignin content provides high glucose yields on enzymatic hydrolysis under all pretreatment conditions, including the control (no pretreatment).

\section{ACKNOWLEDGMENTS}

This project was supported by the United States Department of Agriculture (USDA) National Institute of Food and Agriculture (NIFA) National Needs Fellowship (NNF) program, USDA NIFA grant \# 2012-38420-30203. Acknowledgement also goes to the North Carolina State University Biotechnology group and National Science Foundation (NSF) for the genetically-modified Populus specimens. In addition, this paper is based upon work supported by the U.S. Department of Energy, Office of Science, Office of Workforce Development for Teachers and Scientists, Office of Science Graduate Student Research (SCGSR) program. The SCGSR program is administered by the Oak Ridge Institute for Science and Education for the DOE under contract number DE-AC0506OR23100. 


\section{REFERENCES CITED}

Akhtar, M., Blanchette, R. A., and Kirk, T. K. (1997). "Fungal delignification and biomechanical pulping of wood," in: Biotechnology in the Pulp and Paper Industry, K. Eriksson (ed.), Springer, Berlin, pp. 159-195. DOI: 10.1007/BFb0102074

Alvira, P., Tomás-Pejó, E., Ballesteros, M., and Negro, M. J. (2010). "Pretreatment technologies for an efficient bioethanol production process based on enzymatic hydrolysis: A review," Bioresource Technology 101(13), 4851-4861. DOI: 10.1016/j.biortech.2009.11.093

Blanchette, R. A. (1991). "Delignification by wood-decay fungi," Annual Review of Phytopathology 29(1), 381-403. DOI: 10.1146/annurev.py.29.090191.002121

Blanchette, R. A., Krueger, E. W., Haight, J. E., Akhtar, M., and Akin, D. E. (1997). "Cell wall alterations in loblolly pine wood decayed by the white-rot fungus, Ceriporiopsis subvermispora," Journal of Biotechnology 53, 203-213. DOI: 10.1016/S0168-1656(97)01674-X

Chen, F., and Dixon, R. A. (2007). "Lignin modification improves fermentable sugar yields for biofuel production," Nature Biotechnology 25(7), 759-761. DOI: $10.1038 / \mathrm{nbt} 1316$

Choi J.-W., Choi, D.-H., Ahn, S.-H., Lee, S.-S., Kim, M.-K., Meier, D., Faix, O., and Scott, G. M. (2006). "Characterization of trembling aspen wood (Populus tremuloides 1.) degraded with the white rot fungus Ceriporiopsis subvermispora and MWLS isolated thereof," Holz Roh Werkstoff 64(5), 415-422. DOI: 10.1007/s00107-0060133-9

Coleman, H. D., Samuels, A. L., Guy, R. D., and Mansfield, S. D. (2008). "Perturbed lignification impacts tree growth in hybrid poplar - A function of sink strength, vascular integrity, and photosynthetic assimilation," Plant Physiology 148 (3), 12291237. DOI: $10.1104 /$ pp. 108.125500

Davis, M. F., Schroeder, H., and Maciel, G. (1994). "Solid-state 13C nuclear magnetic resonance studies of wood decay, II. White rot decay of paper birch," Holzforschung 48, 186-192. DOI: 10.1515/hfsg.1994.48.3.186

Decker, S. R., Brunecky, R., Tucker, M. P., Himmel, M. E., and Selig, M. J. (2009). "High-throughput screening techniques for biomass conversion," Bioenergy Research 2(4), 179-92. DOI: 10.1007/s12155-009-9051-0

Decker, S. R., Sykes, R. W., Turner, G. B., Lupoi, J. S., Doepkke, C., Tucker, M. P., Schuster, L. A., Mazza, K., Himmel, M. E., Davis, M. F., and Gjersing, E. (2015). "High-throughput screening of recalcitrance variations in lignocellulosic biomass: Total lignin, lignin monomers, and enzymatic sugar release," Journal of Visualized Experiments 103, Article ID e53163. DOI: 10.3791/53163

Edmunds, C. W., Peralta, P., Sharma-Shivappa, R., Giles, R. L., Kelley, S., Chiang, V. (2016). "Fungal degradation method development for small wood samples subjected to Ceriporiopsis subvermispora," Wood and Fiber Science 48, 70-79.

Eriksson, K., Blanchette, R. A., and Ander, P. (1990). Microbial and Enzymatic Degradation of Wood and Wood Components, Springer, Berlin. DOI: 10.1007/978-3642-46687-8

van Erven, G, Hilgers, R., de Waard, P., Gladbeek, E-J., van Gladbeek, W. J. H., Kabel, M. A. (2019). "Elucidation of in situ ligninolysis mechanisms of the selective whiterot fungus Ceriporiopsis subvermispora," ACS Sustainable Chemistry \& Engineering 7(19), 16757-16764. 
Fernandez-Fueyo, E, Ruiz-Dueñas, F. J., Ferreira, P., Floudas, D., Hibbett, D. S., Canessa, P., Larrondo, L. F., James, T. Y., Seelenfreund, D., Lobos, S., et al. (2012). "Comparative genomics of Ceriporiopsis subvermispora and Phanerochaete chrysosporium provide insight into selective ligninolysis," Proceedings of the National Academy of Sciences 109(14), 5458-5463. DOI: 10.1073/pnas.1206295109

Gaskell, J., Marty, A., Mozuch, M., Kersten, P. J., BonDurant, S. S., Sabat, G., Azarpira, A., Ralph, J., Skyba, O., et al. (2014). "Influence of Populus genotype on gene expression by the wood decay fungus Phanerochaete chrysosporium," Applied and Environmental Microbiology 80(18), 5828-5835. DOI: 10.1128/AEM.01604-14

Giles, R. L., Peszlen, I., Peralta, P., Chang, H. M., Farrell, R., Grand, L., and Horvath, B. (2012). "Fungal biodegradation of genetically modified and lignin-altered quaking aspen (Populus tremuloides Michx.)," Holzforschung 66(1), 105-110. DOI: 10.1515/HF.2011.144

Giles, R. L., Galloway, E. R., Elliott, G. D., and Parrow, M. W. (2011). "Two-stage fungal biopulping for improved enzymatic hydrolysis of wood," Bioresource Technology 102(17), 8011-8016. DOI: 10.1016/j.biortech.2011.06.031

Katahira, R., and Nakatsubo, R. (2001). "Determination of nitrobenzene oxidation products by GC and 1H-NMR spectroscopy using 5-iodovanillin as a new internal standard," Journal of Wood Science 47(5), 378-382. DOI: 10.1007/BF00766789

Keller, F. A., Hamilton, J. E., and Nguyen, Q. A. (2003). "Microbial pretreatment of biomass," Applied Biochemistry and Biotechnology 105(3), 27-41. DOI: 10.1385/ABAB:105:1-3:27

Kirk, T. K., and Cowling, E. B. (1984). "Biological decomposition of solid wood," in: The Chemistry of Solid Wood, R. Rowell (ed.), ACS Publications, Washington, D.C., pp. 455-487. DOI: 10.1021/ba-1984-0207.ch012

Lapierre, C. (2010). "Determining lignin structure by chemical degradations," in: Lignin and Lignans: Advances in Chemistry, C. Heitner, D. R. Dimmel, J. A. Schmidt (eds.), CRC Press, Boca Raton, FL, USA, pp. 11-48. DOI: 10.1201/EBK1574444865-c2

Li, Q., Song, J., Peng, S., Wang, J. P., Qu, G.-Z., Sederoff, R. R., and Chiang, V. L. (2014). "Plant biotechnology for lignocellulosic biofuel production," Plant Biotechnology Journal 12(9), 1174-1192. DOI: 10.1111/pbi.12273

Li, X., and Zheng, Y. (2019). "Biotransformation of lignin: Mechanisms, applications and future work," Biotechnology Progress 36. DOI: 10.1002/btpr.2922

Martínez, A. T., Speranza, M., Ruiz-Dueñas, F. J., Ferreira, P., Camarero, S., Guillén, F., Martínez, M. J., Gutiérrez, A., and del Río, J. C. (2005). "Biodegradation of lignocellulosics: Microbial, chemical, and enzymatic aspects of the fungal attack of lignin," International Microbiology: The Official Journal of the Spanish Society for Microbiology 8(3), 195-204. DOI: 10.13039/501100003339

Miller, Z. D., Peralta, P. N., Mitchell, P., Chiang, V. L., Kelley, S. S., Edmunds, C. W., and Peszlen, I. (2019). "Anatomy and chemistry of Populus trichocarpa with genetically modified lignin content," BioResources 14(3), 5729-5746.

Min, D., Li, Q., Jameel, H., Chiang, V. L., and Chang, H.-M. (2012). "The cellulasemediated saccharification on wood derived from transgenic low-lignin lines of black cottonwood (Populus trichocarpa)," Applied Biochemistry and Biotechnology 168(4), 947-955. DOI: 10.1007/s12010-012-9833-2

Mood, S. H., Golfeshan, A. H., Tabatabaei, M., Jouzani, G. S., Najafi, G. H., Gholami, M., and Ardjmand, M. (2013). "Lignocellulosic biomass to bioethanol, A comprehensive review with a focus on pretreatment," Renewable and Sustainable 
Energy Reviews 27, 77-93. DOI: 10.1016/j.rser.2013.06.033

Mosier, N., Wyman, C., Dale, B., Elander, R., Lee, Y. Y., Holtzapple, M., and Ladisch, M. (2005). "Features of promising technologies for pretreatment of lignocellulosic biomass," Bioresource Technology 96(6), 673-686. DOI: 10.1016/j.biortech.2004.06.025

Novaes, E., Kirst, M., Chiang, V. L., Winter-Sederoff, H., and Sederoff, R. (2010). "Lignin and biomass: A negative correlation for wood formation and lignin content in trees," Plant Physiology 154(2), 555-561. DOI: 10.1104/pp.110.161281

Obst, J. R., Highley, T. L., and Miller, R. B. (1994). "Influence of lignin type on the decay of woody angiosperms by Trametes versicolor," in: Mycotoxins, Wood Decay, Plant Stress, Biocorrosion, and General Biodeterioration, G. C. Llewellyn, W. V. Dashek, and C. E. O’Rear (eds.), Plenum Press, New York, pp. 357-374. DOI: 10.1007/978-1-4757-9450-2_27

Otjen, L., Blanchette, R., Effland, M., and Leatham, G. (1987). "Assessment of 30 white rot basidiomycetes for selective lignin degradation," Holzforschung 41(6), 343-349. DOI: 10.1515/hfsg.1987.41.6.343

Ralph, J., Akiyama, T., Coleman, H. D., and Mansfield, S. D. (2012). "Effects on lignin structure of coumarate 3-hydroxylase downregulation in poplar," BioEnergy Research 5(4), 1009-1019. DOI: 10.1007/s12155-012-9218-y

Reid, I. D., Bourbonnais, R., and Paice, M. G. (2010). "Biopulping and biobleaching," in: Lignin and Lignans: Advances in Chemistry, C. Heitner, D. R. Dimmel, J. A. Schmidt (eds.), CRC Press, Boca Raton, FL, USA, pp. 521-554. DOI:

10.1201/EBK1574444865-c15

Rezania, S., Oryani, B., Cho, J., Talaiekhozani, A., Sabbagh, F., Hashemi, B., Rupani, P. F., and Mohammadi, A. A. (2020). "Different pretreatment technologies of lignocellulosic biomass for bioethanol production: An overview," Energy 199. DOI: 10.1016/j.energy.2020.117457.

Sankaran, R., Cruz, R. A. P., Pakalapati, H., Show, P. L., Ling, R. C., Chen, W-H., and Tai, Y. (2020). "Recent advances in the pretreatment of microalga and lignocellulosic biomass: A comprehensive review," Bioresource Technology 298. DOI: 10.1016/j.biortech.2019.122476.

Salvachúa, D., Prieto, A., López-Abelairas, M., Lu-Chau, T., Martínez, A. T., and Martínez, M. J. (2011). "Fungal pretreatment: An alternative in second-generation ethanol from wheat straw," Bioresource Technology 102(16), 7500-7506. DOI: 10.1016/j.biortech.2011.05.027

Sawada, T., Nakamura, Y., Kobayashi, F., Kuwahara, M., and Watanabe, T. (1995). "Effects of fungal pretreatment and steam explosion pretreatment on enzymatic saccharification of plant biomass," Biotechnology and Bioengineering 48(6), 719724. DOI: 10.1002/bit.260480621

Scott, G. M., Akhtar, M., Lentz, M. J., and Swaney, R. E. (1998). "Engineering, scale-up, and economic aspects of fungal pretreatment of wood chips," in: Environmentally Friendly Technologies for the Pulp and Paper Industry, R. A. Young and M. Akhtar (eds.), Wiley, Hoboken, NJ, USA, pp. 341-384.

Shi, J., Sharma-Shivappa, R. R., Chinn, M., and Howell, N. (2009). "Effect of microbial pretreatment on enzymatic hydrolysis and fermentation of cotton stalks for ethanol production," Biomass and Bioenergy 33(1), 88-96. DOI:

10.1016/j.biombioe.2008.04.016

Shirkavand, E., Baroutian, S., Gapes, D. J., and Young, B. R. (2016). “Combination of 
fungal and physicochemical processes for lignocellulosic biomass pretreatment - A review," Renewable and Sustainalbe Energy Reviews 54, 217-234. DOI: 10.1016/j.rser.2015.10.003

Skyba, O., Douglas, C. J., and Mansfield, S. D. (2013). "Syringyl-rich lignin renders poplars more resistant to degradation by wood decay fungi," Applied and Environmental Microbiology 79(8), 2560-2571. DOI: 10.1128/AEM.03182-12

Studer, M. H., DeMartini, J. D., Davis, M. F., Sykes, R. W., Davison, B., Keller, M., Tuskan, G. A., and Wyman, C. E. (2011). "Lignin content in natural populus variants affects sugar release," Proceedings of the National Academy of Sciences of the United States of America 108(15), 6300-6305. DOI: 10.1073/pnas.1009252108

Sykes, R., Yung, M., Novaes, E., Kirst, M., Peter, G., and Davis, M. (2009). "Highthroughput screening of plant cell-wall composition using pyrolysis molecular beam mass spectroscopy," in: Biofuels: Methods and Protocols, Methods in Molecular Biology, J. R. Mielenz (ed.) Humana Press, Totowa, NJ, USA. DOI: 10.1007/978-160761-214-8_12

Tanaka, H., Koike, K., Itakura, S., and Enoki, A. (2009). "Degradation of wood and enzyme production by Ceriporiopsis subvermispora," Enzyme and Microbial Technology 45(5), 384-390. DOI: 10.1016/j.enzmictec.2009.06.003

Vasco-Correa, J., and Li., Y. (2015). "Solid-state anaerobic digestion of fungal pretreated Miscanthus sinensis harvested in two different seasons," Bioresource Technology 185, 211-217: DOI: 10.1016/j.biortech.2015.02.099.

Vasco-Correa, J., Ge, X., and Li, Y. (2016). "Fungal pretreatment of non-sterile miscanthus for enhanced enzymatic hydrolysis," Bioresource Technology 203, 118 123: DOI: 10.1016/j.biortech.2015.12.018.

Vasco-Correa, J., Luo, X., Li, Y., and Shah, A. (2019). "Comparative study of changes in composition and structure during sequential fungal pretreatment of non-sterile lignocellulosic feedstocks," Industrial Crops \& Products 133, 383-394. DOI: 10.1016/j.indcrop.2019.03.043

Voelker, S. L., Lachenbruch, B., Meinzer, F. C., Jourdes, M., Ki, C., Patten, A. M., Davin, L. B., Lewis, N. G., Tuskan, G. A., Gunter, L., et al. (2010). “Antisense downregulation of 4CL expression alters lignification, tree growth, and saccharification potential of field-grown poplar," Plant Physiology 154(2), 874-886. DOI: 10.1104/pp.110.159269

Wan, C., and Li, Y. (2010). "Microbial delignification of corn stover by Ceriporiopsis subvermispora for improving cellulose digestibility," Enzyme and Microbial Technology 47(1-2), 31-36. DOI: 10.1016/j.enzmictec.2010.04.001

Wan, C., and Li, Y. (2011). "Effectiveness of microbial pretreatment by Ceriporiopsis subvermispora on different biomass feedstocks," Bioresource Technology 102(16), 7507-7512. DOI: 10.1016/j.biortech.2011.05.026

Wan, C., and Li, Y. (2012). "Fungal pretreatment of lignocellulosic biomass," Biotechnology Advances 30 (6), 1447-1457. DOI: 10.1016/j.biotechadv.2012.03.003

Wang, J. P., Matthews, M. L., Williams, C. M., Shi, R., Yang, C., Tunlaya-Anukit, S., Chen, H.-C., Li, Q., Liu, J., Lin, C.-Y., et al. (2018). "Improving wood properties for wood utilization through multi-omics integration in lignin biosynthesis," Nature Communications 9(1), Article ID 1579. DOI: 10.1038/s41467-018-03863-Z

Wang, W., Yuan, T., Cui, B., and Dai, Y. (2013). "Investigating lignin and hemicellulose in white rot fungus-pretreated wood that affect enzymatic hydrolysis," Bioresource Technology 134, 381-385. DOI: 10.1016/j.biortech.2013.02.042 
Wang, W., Yuan, T., Wang, K., Cui, B., and Dai, Y. (2012). "Combination of biological pretreatment with liquid hot water pretreatment to enhance enzymatic hydrolysis of Populus tomentosa," Bioresource Technology 107, 282-286. DOI: 10.1016/j.biortech.2011.12.116

Xiao, L. P., Sun, Z. J., Shi, Z. J., Xu, F., and Sun, R. C. (2011). "Impact of hot compressed water pretreatment on the structural changes of woody biomass for bioethanol production," BioResources 6(2), 1576-1598.

Ziebell, A., Gracom, K., Katahira, R., Chen, F., Pu, Y. Q., Ragauskas, A., Dixon, R. A., and Davis, M. (2010). "Increase in 4-coumaryl alcohol units during lignification in alfalfa (Medicago sativa) alters the extractability and molecular weight of lignin," Journal of Biological Chemistry 285(50), 38961-3868. DOI:

10.1074/jbc.M110.137315

Article submitted: Feb. 19, 2020; Peer review completed: April 18, 2020; Revised version received and accepted: June 3, 2020; Published: July 6, 2020.

DOI: 10.15376/biores.15.3.6488-6505 